\title{
Burning Velocities and Flammability Limits of Premixed Methane/Air/Diluent Flames in Microgravity
}

\author{
Li Qiao*, Werner J.A. Dahm ${ }^{\dagger}$, and Gerard M. Faeth ${ }^{\ddagger}$ \\ The University of Michigan, Ann Arbor, MI, 48109-2140, USA \\ and \\ Elaine S. Oran ${ }^{\S}$ \\ Naval Research Laboratory, Washington, D.C., 20375, USA
}

\begin{abstract}
Laminar burning velocities and flammability limits of premixed methane/air flames in the presence of various inert gases including helium, argon, nitrogen and carbon dioxide were investigated by combined use of microgravity experiments and computations. The experiments used a short-drop free-fall laboratory facility that can eliminate the effect of buoyancy on flames and therefore enable accurate measurements of burning velocities, especially the near-limit values. Burning velocities were measured for outwardly propagating spherical $\mathrm{CH}_{4} /$ air flames with varying concentrations of $\mathrm{He}, \mathrm{Ar}, \mathrm{N}_{2}$ and $\mathrm{CO}_{2}$. Flame behavior was also computed using the steady, one-dimensional laminar premixed flame code PREMIX. Results showed the capability of the diluents to reduce flame speed increases in the order $\mathrm{He}<\mathrm{Ar}<\mathrm{N}_{2}<\mathrm{CO}_{2}$, due to their increased specific heat and decreased transport rates. The measured burning velocities are generally in good agreement with computations. Flammability limits were determined experimentally by finding the limiting concentration of diluents for which combustion can be initiated and propagated throughout the combustion chamber. It was found the limiting concentration for helium is lower than that for argon, indicating helium might be more effective near the limit. The $\mathrm{Ar}, \mathrm{N}_{2}$ and $\mathrm{CO}_{2}$ mixtures at extinction correspond to low burning velocities, $2-3 \mathrm{~cm} / \mathrm{s}$. The helium mixture at extinction, however, corresponds to large burning velocity, about $18 \mathrm{~cm} / \mathrm{s}$. This behavior may be due to the high diffusivity of helium that causes rapid increase of the minimum ignition energy.
\end{abstract}

\section{Introduction}

Gravity has significant influences on near-limit behavior of premixed flames ${ }^{1}$. The flammability limits obtained at $1 \mathrm{~g}$ and $\mu \mathrm{-g}$ are generally different. Near-limit burning velocities are difficult to measure at $1-\mathrm{g}$ because the natural convection caused severe flame front distortion. In a previous study involving outwardly propagating spherical flames ${ }^{2}$, we showed near-limit flames at 1-g propagated upward and formed a classic mushroom shape due to buoyancy. The resulting non-spherical shape limited accurate determination of flame speed. Using a novel onemeter free-fall laboratory facility ${ }^{2}$, however, the near-limit flames were shown to maintain a highly spherical shape

\footnotetext{
* Graduate Student Research Assistant, Department of Aerospace Engineering. Currently Assistant Professor, School of Aeronautics \& Astronautics, Purdue University, lqiao@purdue.edu

${ }^{\dagger}$ Professor \& Head, Laboratory for Turbulence and Combustion (LTC), Department of Aerospace Engineering. Fellow AIAA.

A.B. Modine Distinguished University Professor, Department of Aerospace Engineering. Fellow AIAA.

$\S$ Senior Scientist, Laboratory for Computational Physics and Fluid Dynamics. Fellow AIAA.
} 
that allows their laminar burning velocity to be accurately inferred from measurements of the resulting flame radius versus time.

Chemically inert diluents such as helium, argon, nitrogen, and carbon dioxide are an important class of fire extinguishing agents because of their relatively benign effects on people and equipment. Such diluents may be essential, for example, for extinguishing fires in confined environments such as spacecraft. Most recently, the extinguishing mechanisms of these diluents have been studied for various flame configurations at microgravity ${ }^{3-6}$. In a pervious study $^{7}$, we presented measurements of burning velocities under microgravity conditions for $\mathrm{H}_{2} /$ air/diluent premixed flames at various fuel-equivalence ratios and pressures using the one-meter free-fall facility. We then compared the measured flame speeds to computations with detailed $\mathrm{H}_{2} / \mathrm{O}_{2}$ chemistry and transport properties, and showed the agreement between measured and computed laminar burning velocities was better than it was near the limit. We also analyzed possible causes for the observed discrepancies in the near-limit laminar burning velocities and found that inaccuracies in three-body termination rates for $\mathrm{H}+\mathrm{O}_{2}+\mathrm{M}=\mathrm{HO}_{2}+\mathrm{M}$ reactions and in mass diffusion coefficients for $\mathrm{H}_{2}$ diffusion are the most likely explanation for the near-limit differences.

In the present work, we extend burning velocity measurements to methane/air/diluent flames using the microgravity facility mentioned above. The objective is to understand the extinguishing processes of premixed methane-air flames by various inert gases and to provide better validity of the current $\mathrm{C} / \mathrm{H} / \mathrm{O}$ reaction mechanism for laminar flame propagation, especially in the near-limit region where flame temperature and burning velocity are low. We first present measurements of burning velocities of stoichiometric $\mathrm{CH}_{4} /$ Air/Diluent mixtures at NTP at varying concentrations of helium, argon, nitrogen and carbon dioxide. The measured velocities are then compared with previous experimental data and with computations using the detailed reaction mechanism GRI-Mech 3.0 and an optically-thin radiation model. Flammability limits were determined experimentally by finding the limiting concentration of diluents for which combustion can be initiated and propagated throughout the combustion chamber. It was found the limiting concentration for helium is lower than that for argon. This behavior may be due to the high diffusivity of helium that causes rapid increase of the minimum ignition energy. Effects of diluents on flame structure and radical behavior are also discussed. Finally sensitivity analyses are carried out to identify the most important reactions for highly-diluted flames.

\section{Experiment Description}

The experimental methods are similar to earlier work $^{2}$ and will be described only briefly here. The free-fall facility consists of a support tower, a free-falling spherical combustion chamber, a spark generator, a deceleration box, and shadowgraph optics that record the flame propagation as the chamber falls. The free-fall chamber was held at the top of the tower by an electromagnet before being dropped. As the chamber was released, a hall-effect sensor detected the motion and sent a trigger pulse to the delay generator. A short delay was then provided to allow oscillations from the chamber release to decay to sufficiently low levels. After the delay, the generator sent out two signals, one of which triggered a high-voltage spark generator connected to electrodes that ignited the mixture, and the other triggered a high-speed digital video camera which recorded shadowgraph images of the flame propagation within the free-falling chamber. The two electrodes that generated a spark at the center of the chamber consist of $250 \mu \mathrm{m}$ diameter tungsten wires having free lengths of $40 \mathrm{~mm}$. The spark gap was adjusted from 0.5-3.0 mm, with larger gaps used to ignite flames having high diluent concentrations that require larger ignition energies. The spark energy was supplied by a high-voltage capacitive discharge circuit with an adjustable 0-30 kV voltage and a discharge time of roughly $5 \mu \mathrm{s}$. The spark gap and spark energy were adjusted be to as close as possible to the minimum ignition energies.

The present measurements were restricted to flames having diameters $10 \mathrm{~mm}<d<60 \mathrm{~mm}$. The lower limit provides sufficient time for disturbances introduced by ignition to decay, while the upper limit limits the pressure rise in the chamber during the measuring period to less than $0.7 \%$ of the initial pressure. No results were considered where the flame surface was found to be wrinkled due to flame instabilities. Similar to previous measurements of laminar premixed flame properties ${ }^{2,7}$, measurements were also limited to $\delta_{D} / r_{f}<0.05$ where $\delta_{D}$ is the characteristic 
flame thickness and $r_{f}$ is flame radius, so that effects of curvature and transient phenomena associated with large flame thickness during the early stages of flame formation were small. Under these assumptions, quasi-steady expressions for the local laminar burning velocity and flame stretch are given by ${ }^{8}$

$$
S_{L}=\frac{\rho_{b}}{\rho_{u}} \frac{d r_{f}}{d t}, K=\frac{2}{r_{f}} \frac{d r_{f}}{d t}
$$

where $S_{L}$ is the observed stretched flame propagation speed into the unburned gas and $K$ is the flame stretch. The density ratio needed to find $S_{L}$ was computed assuming adiabatic constant-pressure combustion with the same concentrations of elements in the unburned gases. These calculations were carried out using the adiabatic equilibrium algorithms of McBride et al. ${ }^{9}$ The flame propagation velocity, $d r_{f} / d t$, was obtained from the flame radius $r_{f}(t)$ as measured from the shadowgraph images along the direction perpendicular to the spark electrodes, where disturbances of the flame surface by the electrodes were minimal.

From Markstein ${ }^{10}$ and Clavin $^{11}$, the laminar burning velocity $S_{L}$ is related to the flame stretch $K$ for small to moderate values of curvature and stretch,

$$
S_{L}=S_{L \infty}-L K
$$

The Markstein length $L$ is a measure of the flame response to the stretch rate $K$, and can be either positive (preferential-diffusion stable) or negative (preferential-diffusion unstable), depending on the reactants. The unstretched laminar burning velocities $S_{L \infty}$ were obtained by extrapolating the measured stretched laminar burning velocities $S_{L}(K)$ as a function of the local stretch rate $K$ to zero stretch. Experimental conditions for $\mathrm{CH}_{4} /$ air/diluent flames are summarized in Table 1, as follows: reactant mixtures at room temperature $(298 \pm 0.5 \mathrm{~K})$, a fuel-equivalence ratio of 1.0 , a pressure of $1.0 \mathrm{~atm}$, and diluent concentrations from $0 \%$ to the extinction limit for helium, argon, nitrogen and carbon dioxide.

\section{Computational Method}

Numerical calculations of the corresponding plane unstretched premixed flames were carried out using the steady, one-dimensional laminar premixed flame code PREMIX ${ }^{12}$. The numerical algorithm employs self-adaptive gridding to deal with regions where property gradients are large. The computational grid in space was varied to insure numerical accuracy. CHEMKIN is used as a preprocessor to determine thermochemical and transport properties from the database of Kee et al. ${ }^{13-15}$. Present calculations use detailed chemical reaction mechanism GRIMech $3.0^{16}$, which involves 325 reactions and 53 species. Previous studies show that radiative heat losses become increasingly important in microgravity as the flame propagation becomes slower. Here we use an optically-thin model to simulate radiative heat loss from the hot reaction zone. The Planck mean absorption coefficients are taken 
from the work by Ju et al. ${ }^{17}$ based on the statistical narrow-band model (SNB) with exponential-tailed inverse line strength distribution. The resulting computed unstretched burning velocities were compared for each diluent type and concentration with the corresponding measured values obtained as described above. The predicted flame structures were also discussed for undiluted and diluted flames. Finally, the sensitivities of the computed laminar burning velocities to the reactions of the present chemical kinetic mechanism were evaluated.

\section{Results and Discussion}

\section{A. Flame Evolution}

Similar to previous studies ${ }^{2}$, for undiluted or moderately-diluted mixtures corresponding to $S_{L \infty}>20 \mathrm{~cm} / \mathrm{s}$, the observed flame front remained spherical throughout the measurement in 1-g. In such cases, the laminar burning velocities obtained in 1-g and $\mu-\mathrm{g}$ experiments are essentially the same. For more highly-diluted slower-burning mixtures, however, flames in 1-g become noticeably buoyant, with the flame reaching the top of the chamber before the bottom. At very high dilution levels corresponding to slowly-burning near-limit mixtures, a flame at 1-g cannot even propagate downward against the flow induced by buoyancy. As a result, experiments in microgravity are essential for measuring the near-limit flame speed.

For all the flames considered here, flame surface remained smooth at the early stage of the propagation process and no preferential diffusion instability was observed. Ignition sparks could result in irregular ignition kernels initially but the irregular structures were immediately smoothed out. Later on, hydrodynamic instability was developed for all flames. It was identified by the development of a somewhat regular cellular disturbance pattern on the flame surface. This instability was only observed for flame diameters very large so that they did not affect present measurements that were limited to flame diameters that were smaller than $60 \mathrm{~mm}$.

\section{B. Burning Velocities}

Figure 1 shows the measured and computed burning velocities as functions of the molar concentration of diluents for stoichiometric $\mathrm{CH}_{4} /$ air flames at normal temperature and pressure (NTP). The diluents considered are nitrogen, carbon oxide, helium and argon. The laminar burning velocities presented here are unstretched values, $S_{L_{\infty} \text {, }}$ determined by applying Eq. 2 to the measured values of $S_{L}$ and $K$. All the flames measured here have smooth flame surface in the early stage of flame propagation. Effect of flame stretch on burning velocity is not significant for the stoichiometric $\mathrm{CH}_{4} /$ air flames diluted with nitrogen, argon or carbon dioxide. As shown in Table 1, these mixtures have near-unity Lewis numbers and present near-neutral preferential-diffusion stability. Helium flames have large Lewis number due to the much higher thermal and mass diffusivity. Addition of helium makes the flame become more stable and promotes preferential-diffusion/stretch interactions.

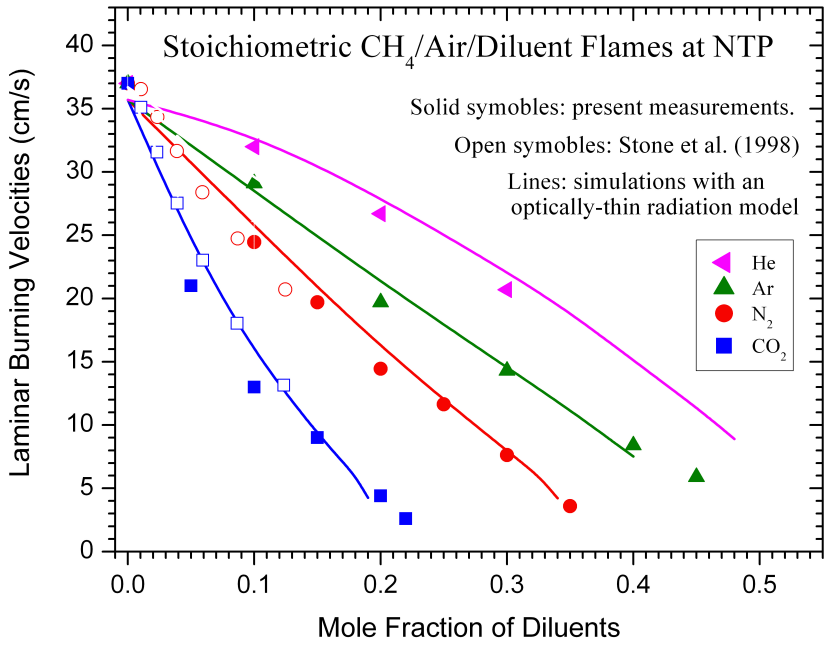

Figure 1. Measured (symbols) and computed (lines) laminar burning velocities as functions of the mole fractions of helium, argon, nitrogen and carbon dioxide for premixed stoichiometric $\mathrm{CH}_{4} /$ air/diluemt flames at NTP.

Measurements of Stone et al. ${ }^{18}$ considering carbon dioxide and nitrogen as diluents are also plotted in Fig. 1 for comparison. Only a limited comparison is 
possible, however, because their data only considered small amount of diluents, up to $12 \%$ in the reactant mixture, and our measurements were extended to high dilution concentrations near extinction limits. The present measurements are generally in good agreement with those of Stone et al. ${ }^{18}$ and with the present simulations using GRI-Mech 3.0 and an optically-thin radiation model. When the concentration of carbon dioxide is moderate, however, Stone et al.'s results have better agreement with our simulations.

The lowest burning velocity $S_{\mathrm{L} \infty}$ that we can accurately measure is around $5 \mathrm{~cm} / \mathrm{s}$. We did observe flames propagating at even lower speeds (probably $2-3 \mathrm{~cm} / \mathrm{s}$ ) that correspond to near-extinction mixtures. Burning velocities of these extremely slow flames, however, could not be accurately determined because they are very weak and thick. They are also greatly influenced by irregular ignition sparks, resulting in non-symmetrical shapes. The results in Fig. 1 show that all diluents considered here cause flame speed to decrease as their concentration is increased. The capabilities of the diluents to reduce burning velocity at any fixed diluent concentration increases in the order $\mathrm{He}<\mathrm{Ar}<\mathrm{N}_{2}<\mathrm{CO}_{2}$, with $\mathrm{CO}_{2}$ being most effective. This can be explained by their increasing specific heats and decreasing transport rates, similar to the conclusion from our previous study ${ }^{7}$.

\section{Flammability Limits}

Flammability limit is a complex phenomenon. From a theoretical point of view, limits arise because mechanisms such as chain-termination reactions, heat losses due to conduction or radiation, and preferentialdiffusion eventually dominate the energy-releasing chemical reactions and cause extinction at the flammability limit. In our study, the flammability limits were determined by systematically varying the composition and ignition energy and bracketing the limiting condition through successive experiment trials. The success ignition was determined by observation of a flame kernel initially produced by the ignition spark and its subsequent propagation throughout the chamber. Failure to ignite was quite distinct and the hot gas kernel from the spark would quickly dissipate. In addition, a pressure transducer was used to tract pressure history within the chamber. Successful ignition of a flame was accompanied with a rapid pressure increase inside the chamber, whereas failure to ignite resulted in no measurable pressure rise after the spark.

Table 2 shows the limiting concentration of each diluent for stoichiometric $\mathrm{CH}_{4} /$ air flames at NTP, in terms of the diluent mole fraction in the reactant mixture, as well as the corresponding diluent mole fraction in the non-fuel gases and the limiting oxygen index. We have shown in Fig. 1 that the capability of diluents to reduce burning velocity increases in the order $\mathrm{He}<\mathrm{Ar}<\mathrm{N}_{2}<\mathrm{CO}_{2}$. For a given diluent concentration, helium flames have higher burning velocities than argon flames due to the much higher thermal diffusivity of helium. The results in Table 2,

Table 2. Flammability Limits of Stoichiometric $\mathrm{CH}_{4} /$ Air/Diluent Flames at NTP:

\begin{tabular}{cccc}
\hline Diluent & $\begin{array}{c}X_{D} \% \\
\text { in reactant } \\
\text { mixture }\end{array}$ & $\begin{array}{c}X_{D} \% \\
\text { in non-fuel } \\
\text { gases }\end{array}$ & $\begin{array}{c}\text { Oxygen } \\
\text { Index }\end{array}$ \\
\hline $\mathrm{He}$ & 38 & 40.4 & 12.5 \\
$\mathrm{Ar}$ & 51 & 53.5 & 9.8 \\
$\mathrm{~N}_{2}$ & 39 & 41.4 & 12.3 \\
$\mathrm{CO}_{2}$ & 22 & 23.8 & 16.0 \\
\hline
\end{tabular}
however, show that in terms of the limiting concentration, the relative ranking of diluent effectiveness is $\mathrm{Ar}<\mathrm{He} \approx \mathrm{N}_{2}<\mathrm{CO}_{2}$. The limiting concentration of helium is lower than that of argon, indicating helium might be more effective than argon near the limit.

The Ar, $\mathrm{N}_{2}$ and $\mathrm{CO}_{2}$ mixtures at extinction correspond to low burning velocities, about 2-3 cm/s. And these mixtures have near-unity Lewis numbers, as shown in Table 1. Thus preferential-diffusion unlikely has impact on the flammability limits. In addition, the effect of buoyancy, which may also affect flammability limit, was essentially eliminated. Moreover, the $180 \mathrm{~mm}$ radius of the present spherical chamber is sufficiently large in comparison with the $r_{f}<30 \mathrm{~mm}$ flames for heat losses by conduction to the walls or to the $250 \mu \mathrm{m}$ tungsten electrodes to also be negligible. Therefore, heat loss due to radiation might be the cause of extinction for these mixtures. The measured burning velocity at limit, which is on the order of a few $\mathrm{cm} / \mathrm{s}$, is consistent with theoretical studies including radiation heat $\operatorname{loss}^{19}$ that showed a limiting flame speed of $2 \mathrm{~cm} / \mathrm{s}$. The helium mixture at extinction, however, has a high burning velocity, about $18 \mathrm{~cm} / \mathrm{s}$. When the helium concentration is above $38 \%$, the reactant mixture cannot be ignited even though very high-energy spark was used. Ronney ${ }^{20}$ showed in a previous 
study that at microgravity, the minimum ignition energy increases rapidly as Lewis number increases. Therefore, the limit for helium shown here may be the ignition limit because extremely high ignition energy is required due to the high diffusivity of helium.

The minimum oxygen index (MOI), which is the minimum concentration of oxygen (in \%) by volume in the nonfuel gases, is a measure of extinction conditions. As can be seen in Table 2, MOI depends on the type of diluent, i.e., $\mathrm{MOI}$ is the highest for $\mathrm{CO}_{2}$ than for others. It also depends on type of the fuel. For the same diluent, MOI for $\mathrm{H}_{2}$ /air flames ${ }^{2}$ is much lower than that for $\mathrm{CH}_{4} /$ air flames both at stoichiometric conditions. This indicates hydrogen flames are much harder to suppress than hydrocarbons.

\section{Flame structures}

To gain a better understanding of the addition of diluents on the structures of laminar premixed flames, numerical simulations of $\mathrm{CH}_{4}$ /air flames in the presence of various diluents were carried out using PREMIX. Figure 2 shows the predicted structures of $\mathrm{CH}_{4} /$ air flames with and without diluents at fuel-equivalence ratio of unity and NTP. Results in Fig. 2 a) provide the baseline flame structure when no diluent is present. Fig. 2 b)-d) provide similar results for the flames with a diluent concentration of $25 \%$ for helium, argon, and nitrogen. All these results are based on the reaction mechanism GRI-Mech 3.0 ${ }^{16}$. In each figure, the left graph provides profiles of temperature and the stable species $\left(\mathrm{CH}_{4}, \mathrm{O}_{2}, \mathrm{CO}_{2}, \mathrm{CO}\right.$, and $\left.\mathrm{H}_{2} \mathrm{O}\right)$ concentrations, whereas the right graph provides profiles of radical species $\left(\mathrm{OH}, \mathrm{H}, \mathrm{O}, \mathrm{HO}_{2}, \mathrm{CH}_{3}, \mathrm{CH}_{2} \mathrm{O}, \mathrm{C}_{2} \mathrm{H}_{4}\right.$, and $\left.\mathrm{C}_{2} \mathrm{H}_{6}\right)$ concentrations, all as a functions of distance through the flame. The results show that the maximum concentrations of the radicals $\mathrm{HO}_{2}, \mathrm{CH}_{3}, \mathrm{CH}_{2} \mathrm{O}, \mathrm{C}_{2} \mathrm{H}_{4}$, and $\mathrm{C}_{2} \mathrm{H}_{6}$ are much smaller than the concentrations of the radicals $\mathrm{OH}, \mathrm{H}$, and $\mathrm{O}$; therefore, the latter tend to dominate reactive effects in the present flames, supporting the importance of the $\mathrm{H} / \mathrm{O}$ kinetics for methane/air flames.

Obviously, due to the dilution, the reactant concentrations $\left(\mathrm{CH}_{4}\right.$ and $\left.\mathrm{O}_{2}\right)$ and product concentration $\left(\mathrm{CO}_{2}\right.$ and $\mathrm{H}_{2} \mathrm{O}$ ) are decreased for the diluted flames comparing to the undiluted flame. We see a progressive reduction of the final flame temperature form $2176 \mathrm{~K}$ (for no diluent) to $1945 \mathrm{~K}$ (for the diluent $\mathrm{He}$ and $\mathrm{Ar}$ ), and to $1840 \mathrm{~K}$ (for the diatomic suppressant $\mathrm{N}_{2}$ ). This behavior is solely due to the progressive increase of specific heat of these diluents in the order of $\mathrm{He}$ and $\mathrm{Ar}$ (the same), and $\mathrm{N}_{2}$. On the other hand, the increased thermal diffusivity of He compared to Ar has no effect on the final flame temperature because these flames are adiabatic. For the present stoichiometric flames, the radical $\mathrm{OH}$ generally has the largest maximum concentrations in the flames, with $\mathrm{H}$ and $\mathrm{O}$ having somewhat smaller maximum concentrations, and with the other radicals all having significantly smaller concentrations. In addition, the maximum concentration of $\mathrm{OH}$ in the flames progressively decreases in the order no diluent, helium, argon and nitrogen. 
a)
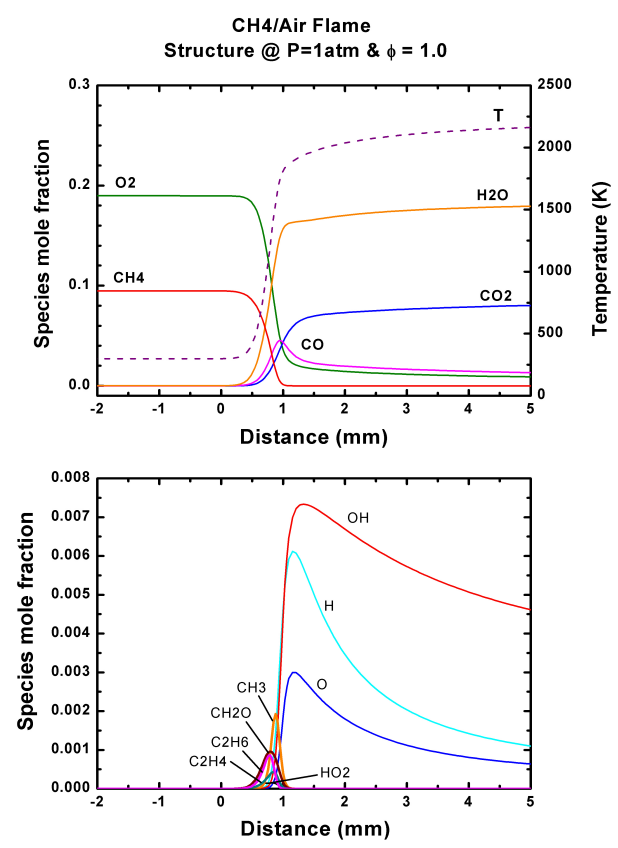

c)
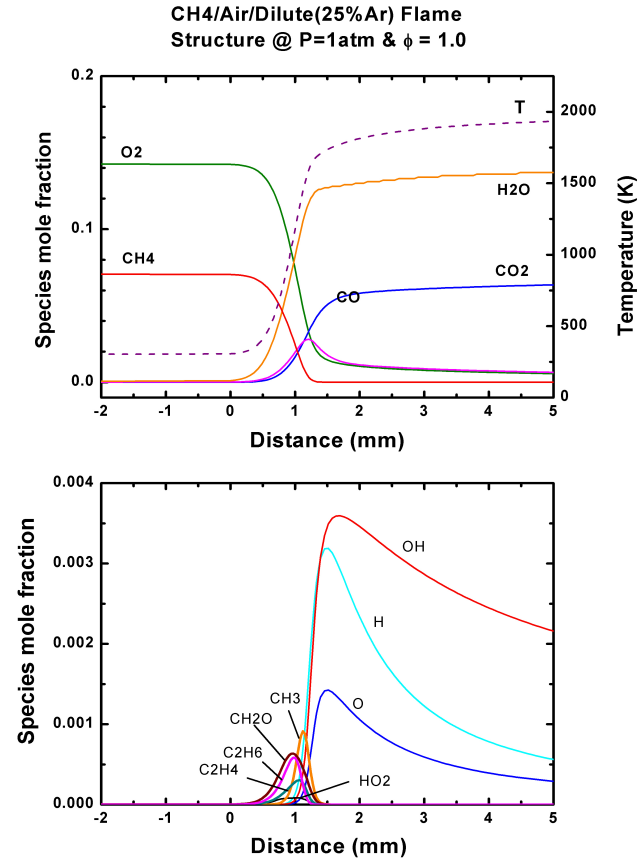

b)
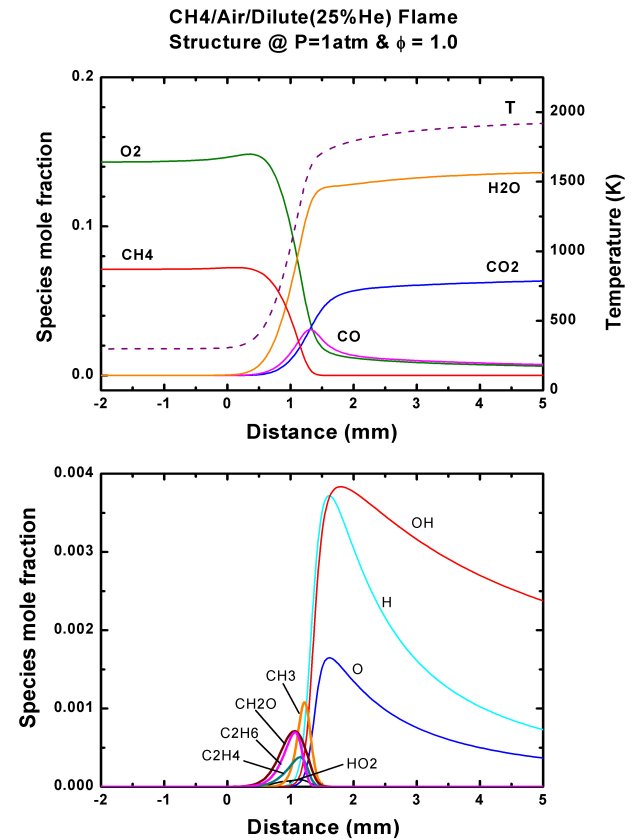

d)
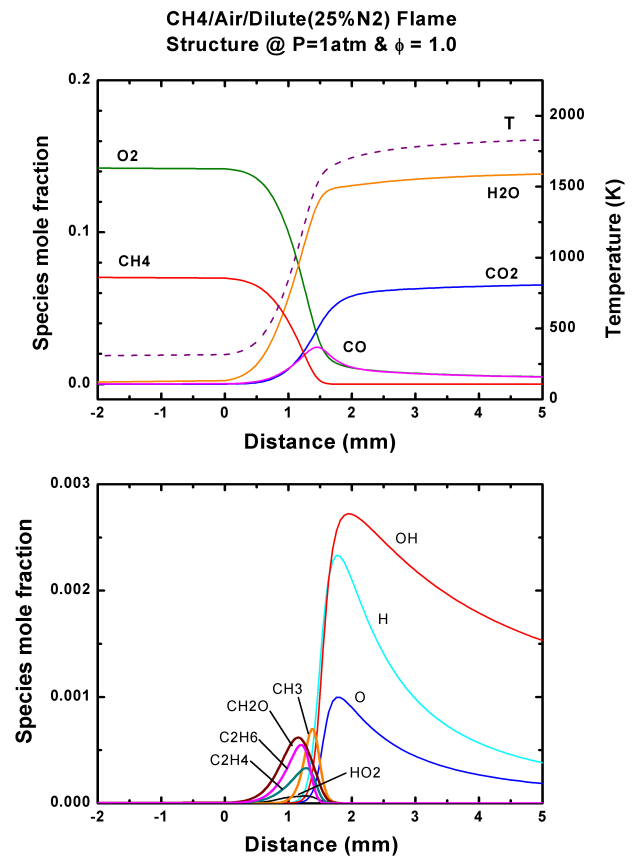

Figure 2. Computed structure of an premixed stoichiometric methane/air flames at NTP: a) without diluent, b) with a $25 \%$ by volume helium, c) with a $25 \%$ by volume argon, d) with a $25 \%$ by volume nitrogen. 


\section{E. Sensitivity Analyses}

Insight about the most important chemical reactions needed to predict the laminar burning velocities of $\mathrm{CH}_{4} /$ air/diluent flames was sought by carrying out sensitivity calculations using the methods described by Kee et al. ${ }^{12}$ and grcar et al. ${ }^{21}$ Figure 3 illustrates the sensitivity coefficients of $S_{L_{\infty}}$ respect to reaction rate coefficients for stoichiometric $\mathrm{CH}_{4} /$ air flames at varying diluent concentrations. The results are normalized sensitivities based on the mass burning rate for diluent $\left(\mathrm{CO}_{2}\right)$ concentration at $0 \%, 15 \%$ and $22 \%$, respectively. The seven reactions presented in the figure exhibit the largest sensitivities.

Chain propagation and branching reactions have positive sensitivities because those reactions increase the concentrations of highly reactive radical species, such as the hydrogen and hydroxyl radicals, and thus promote larger burning rates. In contrast, the recombination reactions, where reactive radicals are converted into stable species, display negative sensitivities because these reactions reduce the available radical species concentrations and thus promote smaller burning rates.

The reactions exhibiting the largest sensitivities at low and high $\mathrm{CO}_{2}$ concentrations are similar: the chain propagation and branching reactions $(\mathrm{H}+\mathrm{O} 2=\mathrm{O}+\mathrm{OH}, \mathrm{OH}+\mathrm{CO}=\mathrm{H}+\mathrm{CO} 2, \mathrm{HO} 2+\mathrm{CH} 3=\mathrm{OH}+\mathrm{CH} 3 \mathrm{O})$ exhibit the largest positive sensitivities, while the recombination reactions $(\mathrm{H}+\mathrm{CH} 3+\mathrm{M}=\mathrm{CH} 4+\mathrm{M}, \mathrm{HCO}+\mathrm{O} 2=\mathrm{HO} 2+\mathrm{CO}$, $\mathrm{H}+\mathrm{O} 2+\mathrm{H} 2 \mathrm{O}=\mathrm{HO} 2+\mathrm{H} 2 \mathrm{O}$ ) exhibit the largest negative sensitivities. At higher $\mathrm{CO}_{2}$ concentrations, the sensitivity of $\mathrm{H}+\mathrm{CH} 3+\mathrm{M}=\mathrm{CH} 4+\mathrm{M}$ become larger because the ternary collision rates increase. Among all the reactions, the reaction $\mathrm{H}+\mathrm{O} 2=\mathrm{O}+\mathrm{OH}$ exhibits the largest sensitivities over the entire diluent concentration range, supporting the importance of the $\mathrm{H} / \mathrm{O}$ kinetics for methane-air flames.

\section{Conclusions}

This study investigated the flame structure, burning velocity, and extinction behavior of premixed methane-air flames in the presence of various inert gases including helium, argon, nitrogen and carbon dioxide. The experiments were conducted in a short-drop free-fall microgravity facility, involving unsteady outwardly propagating spherical laminar premixed flames. Corresponding calculations of flame behavior considered variable transport and thermodynamics properties, radiation model, and the detailed C/H/O chemical kinetic mechanism GRI-Mech 3.0 $0^{16}$.

The measured burning velocities are generally in good agreement with simulations. Similar to our previous results, the capabilities of the diluents to reduce flame speed increase in order of from helium, to argon, nitrogen and carbon dioxide. This mainly reflects their progressively increasing specific heats and progressively decreasing mass and thermal transport properties.

Flammability limits were determined experimentally by finding the limiting concentration of diluents for which combustion can be initiated and propagated throughout the combustion chamber. It was found the limiting concentration for helium is lower than that for argon, indicating helium might be more effective near the limit. The Ar, $\mathrm{N}_{2}$ and $\mathrm{CO}_{2}$ mixtures at extinction correspond to low burning velocities, $2-3 \mathrm{~cm} / \mathrm{s}$. The helium mixture at extinction, however, corresponds to large burning velocity, about $18 \mathrm{~cm} / \mathrm{s}$. This behavior may be due to the high diffusivity of helium that causes rapid increase of the minimum ignition energy. 
Computational results show addition of diluents reduces the adiabatic flame temperature and the concentrations of the radicals $\mathrm{OH}, \mathrm{H}$, and $\mathrm{O}$, by increasing the specific heat of the mixture. Sensitivity analyses show, among all the reactions, the reaction $\mathrm{H}+\mathrm{O} 2=\mathrm{O}+\mathrm{OH}$ exhibits the largest sensitivities over the entire diluent concentration range, supporting the importance of the $\mathrm{H} / \mathrm{O}$ kinetics for methane-air flames. At higher diluent concentrations, the sensitivity of $\mathrm{H}+\mathrm{CH} 3+\mathrm{M}=\mathrm{CH} 4+\mathrm{M}$ become larger because the ternary collision rates increase.

\section{Acknowledgements}

The authors would like to acknowledge the financial support from the Rackham Predoctoral Fellowship at the University of Michigan.

\section{References}

${ }^{1}$ Ronney, P. D., "Premixed-Gas Flames," in: Microgravity Combustion: Fires in Free Fall (H. Ross, Ed.), Academic Press, London, U.K., 2001, pp. 35-82.

${ }^{2}$ Qiao, L., Gu, Y., Dahm, W. J. A., Oran, E. S., and Faeth, G. M., "Near-Limit Laminar Burning Velocities of Microgravity Premixed Hydrogen Flames with Chemically-Passive Fire Suppressants," Proceedings of the Combustion Institute, Vol. 31, 2007, pp. 2701-2709.

${ }^{3}$ Takahashi, F., Linteris, G. T., and Katta V. R., "Extinguishment mechanisms of coflow diffusion flames in a cup-burner apparatus," Proceedings of the Combustion Institute, Vol. 31, 2007, pp. 2721-2729.

${ }^{4}$ Son, Y., and Ronney, P.D., "Radiation-driven flame spread over thermally thick fuels in quiescent microgravity environments," Proceedings of the Combustion Institute, Vol. 29, 2002, pp. 2587-2594.

${ }^{5}$ Shaw, B. D., and Wei, J. B., "Propanol droplet flammability and combustion in air-diluent environments under normal and reduced gravity," Combustion Science and Technology, Vol. 179, 2007, pp. 1205-1223.

${ }^{6}$ Lock, A., Briones, A. M., Aggarwal, S. K., Puri, I. K., and Hegde, U., "Liftoff and extinction characteristics of fuel- and airstream-diluted methane-air flames," Combustion and Flame, Vol.149, 2007, pp. 340-352.

${ }^{7}$ Qiao, L., Gu, Y., Dahm, W. J. A., Oran, E. S., and Faeth, G. M., "A Study of the Effects of Diluents in Near-Limit $\mathrm{H}_{2}$-Air Flames in Microgravity at Normal and Reduced Pressures," Combustion and Flame, Vol.151, 2007, pp. 196-208.

${ }^{8}$ Strehlow, R. A., and Savage, L. D., "The Concept of Flame Stretch," Combustion and Flame, Vol. 31, No. 2, 1978, pp. 209211.

${ }^{9}$ McBride, B. J., Reno, M. A., and Gordon, S., "CET93 and CETPC: An Interim Updated Version of the NASA Lewis Computer Program for Calculating Complex Chemical Equilibrium with Applications", NASA TM 4557, 1994.

${ }^{10}$ Markstein, G. H., Non-Steady Flame Propagation, Pergamon, New York, 1964, p. 22.

${ }^{11}$ Clavin, P., "Dynamic Behavior of Premixed Flame Fronts in Laminar and Turbulent Flows," Progress in Energy and Combustion Science,Vol. 11, No. 1, 1985, pp. 1-59.

${ }^{12}$ Kee, R. J., Grcar, J. F., Smooke, M. D., and Miller, J. A., “A FORTRAN Program for Modeling Steady Laminar OneDimensional Premixed Flames,” Rept. SAND85-8240, Sandia National Labs., Albuquerque, NM, 1993.

${ }^{13}$ Kee, R. J., Dixon-Lewis, G., Warnatz, J., Coltrin, M. E., and Miller, J. A., “A FORTRAN Computer Code Package for the Evaluation of Gas-Phase, Multicomponent Transport Properties," Rept. SAND86-8246, Sandia National Labs., Albuquerque, NM, 1992.

${ }^{14}$ Kee, R. J., Rupley, F. M., and Miller, J. A., "The CHEMKIN Thermodynamic Data Base," Rept. SAND87-8215B, Sandia National Labs., Albuquerque, NM, 1992.

${ }^{15}$ Kee, R. J., Rupley, F. M., and Miller, J. A., "CHEMKIN II: A Fortran Chemical Kinetics Package for the Analysis of Gas Phase Chemical Kinetics,” Rept. SAND89-8009B, Sandia National Labs., Albuquerque, NM, 1993.

${ }^{16}$ Smith, G. P., Golden, G. M, Zrenklach, M., Moriarty, N. W., Eiteneer, B., Goldenberg, M., Bowman, T. C., Hanson, R. K., Song, S., Gardiner, W. C. Jr., Lissianski, V. V., and Qin, Z., http://www.me.berkeley.edu/gri_mech/

${ }^{17} \mathrm{Ju}$, Y., Guo, H., Liu, F., and Maruta, K., "Effects of the Lewis number and radiative heat loss on the bifurcation and extinction of $\mathrm{CH}_{4} / \mathrm{O}_{2}-\mathrm{N}_{2}$-He flames," Journal of Fluid Mechanics, Vol. 379, 1999, pp. 165-190.

${ }^{18}$ Stone, R., Clarke, A., and Beckwith, P., "Correlations for the Laminar-Burning Velocity of Methane/Diluent/Air Mixtures Obtained in Free-Fall Experiments," Combustion and Flame, Vol. 114, 1998, pp. 546-555.

${ }^{19}$ Lakshmisha, K. N., Paul, P. J., Mukunda, H. S., "On the flammability limit and heat loss in flames with detailed chemistry," Proceedings of the Combustion Institute, Vol. 23, 1990, pp. 433-440.

${ }^{20}$ Ronney, P. D., "Effect of Chemistry and Transport Properties on Near-Limit Flames at Microgravity," Combustion Science and Technology, Vol. 59, 1988, pp. 123-141.

${ }^{21}$ Grcar, J. F., Kee, R. J., Smooke, M. D., and Miller, J. A., “A Hybrid Newton/Time-Integration Procedure for the Solution of Steady, Laminar, One-Dimensional Premixed Flames," Proceedings of the Combustion Institute, Vol. 21, 1986, pp. 17731782. 